\title{
PERMISOS, LAGUNAS Y DISCRECIONALIDAD JUDICIAL: RESPUESTA A BULYGIN*
}

\author{
Juan Carlos Bayón \\ Universidad Autónoma de Madrid
}

RESUMEN. En respuesta a la crítica de E. BULYGIN, se analiza en este trabajo si se puede sostener o no que la mera afirmación de que el demandado no tiene la obligación que el demandante le atribuye constituye un fundamento suficiente del deber del juez de desestimar la demanda.

Palabras clave: permisos, lagunas, discrecionalidad judicial.

ABSTRACT. Replying to E. BULYGIN'S criticism, this paper analyses whether or not it can be said that the mere statement that the defendant does not have the obligation attributed to him by the plaintiff is sufficient to justify the conclusion that the judge has the duty to reject the claim.

Keywords: permissions, legal gaps, judicial discretion.

* Fecha de recepción: 15 de abril de 2011. Fecha de aceptación: 9 de mayo de 2011. 


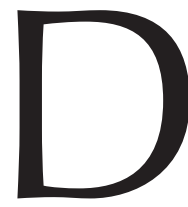

ecía VOLTAIRE que una discusión prolongada es señal de que ambas partes se equivocan. Al menos, diría yo, puede ser señal de que cada parte tiene razón en algo y ninguna de las dos, por tanto, toda la razón de su lado. El texto de E. BuLYGIN y las respuestas al mismo que se incluyen en este número de Doxa son - ¿por ahora? - la última vuelta de tuerca a una discusión en la que han intervenido bastantes personas y que, a estas alturas, bien puede calificarse ya como considerablemente prolongada ${ }^{1}$. Y mi impresión actual, tras tomar en consideración la más reciente réplica de BuLYGIN, es que tal vez quepa aplicarle a esta larga discusión el aforismo volteriano (aunque no estoy muy seguro de que invocar precisamente a VOLTAIRE sea el mejor modo de aplacar a quien, como hace mi buen amigo E. BuLYGIN con su característico e inimitable humor, se impone como misión extirpar la herejía...). Adelanto desde el principio, por consiguiente, mi reconocimiento de que en el trabajo que critica BULYGIN ${ }^{2}$ - aquel en el que la herejía, afirma, «alcanza su apogeo»- incurrí en alguna expresión desafortunada y no supe ser lo bastante claro respecto a un punto que BULYGIN, con su perspicacia habitual, sitúa de inmediato en el centro de su réplica. Pero me temo que los herejes solemos ser tercos, de manera que, admitido lo anterior, no puedo dejar de añadir que aun así hay algo en la posición global de BuLYGIN que sigue sin convencerme.

Con todo - y aunque no se trata en modo alguno de buscar un irenismo facilón-, me atrevería a decir que nuestro desacuerdo puede estar cada vez más cerca de solventarse a medida que críticas, réplicas y dúplicas van consiguiendo establecer cada vez con mayor precisión qué es exactamente lo que cada cual acepta o rechaza de la posición del otro. El último escrito de BULYGIN muestra con lucidez que hay un punto que ciertamente no sería sensato que negáramos ninguno de los que hemos discutido con él sobre este tema, aunque a veces hayamos dado a entender que lo hacíamos. Y confío en que él acabe por aceptar que hay asimismo una idea en la que con mayor o menor acierto hemos intentado insistir sus críticos y de la que sería igualmente poco sensato discrepar,

1 Aunque las etiquetas se asentarían mucho más tarde, las tesis de la «asimetría» y de la «equivalencia pragmática» ya eran expresamente criticadas hace cuarenta años por ALCHOURRón y BULYGIN en el cap. VIII de Normative Systems, donde se afirmaba que se trataba de una doctrina «muy difundida entre los juristas en general y entre los filósofos del Derecho en particular» ( $c f r$. C. E. AlCHOURRón y E. BulYGIN, Normative Systems [1971], trad. cast. de los autores — por donde se cita_, Introducción a la metodología de las ciencias juridicas y sociales, Buenos Aires, Astrea, 1975, 201) y se acababa concretando el blanco de su crítica en la posición de Kelsen. Con posterioridad, los hitos de la polémica son conocidos. Pueden situarse, en primer lugar, en la reivindicación de KELSEN frente a la crítica de ALCHOURRón y Bulygin llevada a cabo por J. RuIZ MANERO, Jurisdicción y normas. Dos estudios sobre función jurisdiccional y teoría del Derecho, Madrid, Centro de Estudios Constitucionales, 1990, 41-45, así como en el debate subsiguiente entre BULYGIN y RUIZ MANERO en los textos de uno y otro contenidos en L. Gianformaggio y S. L. PAulson, Cognition and Interpretation of Law, Torino, Giappichelli, 1995. A continuación —y en su presentación más acabada - en los distintos trabajos incluidos en F. Atria, E. Bulygin, J. J. Moreso, P. Navarro, J. Rodríguez y J. Ruiz Manero, Lagunas en el Derecho. Una controversia sobre el Derecho y la función judicial, Madrid-Barcelona, Marcial Pons, 2005. Aquella discusión tuvo su prolongación o secuela en E. Bulygin, M. AtienZa y J. C. BAYÓN, Problemas lógicos en la teoría y la práctica del Derecho, Madrid, Fundación Coloquio Jurídico Europeo, 2009. Y los trabajos que se incluyen en este número de Doxa — a los que habría que añadir algún otro, como el aún inédito de P. NAVARRO, «Normas permisivas y clausura de los sistemas normativos», Universitat de Girona, Legal Theory and Philosophy Working Papers Series, núm. 22, en http://www.udg.edu/FilosofiadelDret/Workingpapers/tabid/12181/language/ ca-ES/Default.aspx - , constituyen, por el momento, la última ronda de la polémica.

2 Esto es, en J. C. BAYÓN, «Sobre el principio de prohibición y las condiciones de verdad de las proposiciones normativas», en E. Bulygin, M. AtienZa y J. C. BAyón, Problemas lógicos en la teoría y la práctica del Derecho, cit. (en nota 1), 27-73. 
por más que, según creo, él la haya negado. Aun así, qué duda cabe, nuestras respectivas concepciones del Derecho van a seguir estando alejadas en una serie de puntos de no poca importancia. Pero al menos respecto a la cuestión específica de la tan traída y llevada «tesis de la equivalencia pragmática entre la ausencia de regulación y la regulación permisiva», tal vez pueda empezar a vislumbrarse el final de las hostilidades.

\section{1.}

BULYGIN reúne bajo el rótulo «equivalencia pragmática entre permiso y no prohibición» varios debates diferentes, tanto por su contenido como por sus protagonistas. En particular, polemizando con ATIENZA y RuIZ MANERO, discute en las secciones II y III de su artículo si cabe o no sostener que las normas permisivas son superfluas o normativamente irrelevantes y si sus funciones pueden o no ser cumplidas con éxito en todos los casos por medio de normas de obligación o prohibición. Nada diré sobre estas cuestiones, de las que no me ocupé tampoco en el artículo que BULYGIN critica. Los propios ATIENZA y RUIZ MANERO tienen mejor título que yo para responder, si consideran necesario hacerlo. Y de más está decir que, en tal caso, no les haría ninguna falta que yo asumiese el papel de coadyuvante.

Hay otro sentido diferente en el que cabe hablar de una «equivalencia pragmática entre regulación permisiva y ausencia de regulación», que es aquel al que aludí en mi trabajo de 2009, el que ahora critica BuLYGIN en las secciones IV a VI de su artículo y el único del que voy a ocuparme en esta nota. Conviene entonces empezar por precisar qué es lo que traté de sostener en ese trabajo. Mi idea era que, a condición de que se tuviesen en cuenta una serie de precisiones decisivas, cabe decir respecto de las conductas que el Derecho no regula que su realización es permisible en un sentido determinado. Y las precisiones eran esencialmente tres. La primera, que la afirmación iba referida a los supuestos que el Derecho «no regula ni pretende regular», una noción distinguible a mi juicio de la de genuina laguna normativa en un sentido que allí intenté aclarar ${ }^{3}$. La segunda, que tanto para distinguir estas dos últimas nociones como para poder mantener la idea misma de que la realización de las conductas que el Derecho no regula es permisible resultaba crucial distinguir entre calificaciones normativas explícitas o prima facie y calificaciones normativas finales o concluyentes, dado que la afirmación en cuestión había de entenderse referida a las conductas que el Derecho no pretende regular y no regula de manera final o concluyente, no meramente a las que prima facie no regula en tanto en cuanto no las regula explícitamente. Y la tercera, por fin, que el sentido en el que se afirmaba que su realización era permisible no era el de un «permiso protegido», lo que implicaría la obligación de los demás de abstenerse de impedir la realización de la conducta en cuestión, sino el de un «permiso no protegido» —un privilegio hohfeldiano- que, no obstante, no sería «vacío o carente de consecuencias» puesto que implicaría al menos que no teniendo nadie el deber de realizarla ni el de abstenerse de realizarla $-\mathrm{y}$, correlativamente, no teniendo nadie el derecho de exigir a otro que la

\footnotetext{
${ }^{3}$ Y por cierto, respecto de los casos de laguna normativa en sentido estricto sostenía allí de manera muy clara - y sigo pensando- que sitúan al juez en la posición de tener que decidir discrecionalmente: vid. J. C. BAYÓN, «Sobre el principio de prohibición y las condiciones de verdad de las proposiciones normativas», cit. (en nota 2), 60 y 64 .
} 
realice ni el de exigirle que no la realice- - un juez debería desestimar cualquier demanda cuyo petitum se basara en que el demandado está jurídicamente obligado a realizarla o en que está obligado a no realizarla, es decir, cuya pretensión fuese hacer valer derechos que no se tienen. En ese sentido preciso, decía yo, cabría hablar de «equivalencia pragmática» entre regulación permisiva y ausencia de regulación; y dicha equivalencia pragmática vendría de la mano de la «asimetría» entre sentencias estimatorias y desestimatorias, por cuanto en el caso de las segundas, a diferencia de lo que ocurriría con las primeras, el deber del juez de fallar en un sentido determinado no requeriría que haya en el Derecho una norma que regule en un sentido u otro la conducta del demandado.

Explicar con detalle cada uno de esos puntos requeriría reproducir aquí la mayor parte del contenido de mi trabajo de 2009 y no tiene sentido hacerlo. El hipotético lector interesado en los pormenores puede encontrarlos en aquel texto y me permito reenviarle al mismo. Lo que me propongo destacar ahora es que la tesis que mantuve entonces puede entenderse en realidad de dos maneras, una más fuerte y otra más débil: y que la más fuerte — que no voy a negar que puede encontrarse afirmada explícitamente en algunos pasajes de aquel trabajo- es en realidad insostenible. En efecto, si lo que se está diciendo es que de la mera ausencia de prohibición de la conducta del demandado no se sigue sin más que el juez se encuentre en una posición de discrecionalidad a la hora de decidir si acoge o rechaza la demanda, sigo pensando que la idea es correcta. Pero si lo que se está diciendo es en cambio que de la mera ausencia de prohibición de la conducta del demandado se sigue sin más que no está el juez en esa posición de discrecionalidad, entonces hay que reconocer que eso es insostenible: para que en ausencia de prohibición el juez tenga el deber específico de desestimar la demanda hace falta algo más, que no tiene por qué darse necesariamente; y puesto que sería concebible que no se diese, la verdad de la afirmación en cuestión resultará contingente.

Mi propósito fundamental en esta nota consiste, por una parte, en explicar con detalle por qué la posición que yo sostuve, entendida en el segundo y más fuerte de los sentidos apuntados, debe ser revisada. Pero habida cuenta de que si es entendida en el primero y más débil de esos dos sentidos me sigue pareciendo correcta, me propongo asimismo explicar, por otra parte, por qué la posición mantenida por BULYGIN necesita también algún tipo de corrección. Antes de abordar con detalle esas cuestiones, no obstante, introduciré un par de digresiones en las que intento mostrar que dos de las críticas que me formula BULYGIN son inapropiadas.

\section{2.}

Como recordaba hace un momento, en toda esta discusión me parece crucial distinguir con claridad entre la calificación normativa expresa o prima facie de una conducta, que es la que deriva simplemente del sentido literal de las prescripciones explícitas que emite el legislador, y su calificación normativa final o concluyente, que es la que resulta de tomar en cuenta además los principios o razones subyacentes a esas prescripciones. La calificación normativa concluyente puede coincidir o no con la calificación normativa prima facie. Y cuando no coincide, puede ser porque de tomar en cuenta las razones subyacentes resulte la ampliación o restricción del tenor literal 
claro de las prescripciones expresas, la aclaración de problemas de indeterminación de los que pudiese adolecer su formulación, o una regulación determinada de supuestos no contemplados expresamente por ninguna de aquellas prescripciones.

Esa diferencia entre calificaciones normativas prima facie y calificaciones normativas concluyentes me parecía y me sigue pareciendo central para nuestra comprensión del Derecho y no sólo, por cierto, para una intelección adecuada del problema de las lagunas. Que la distinción me parezca esencial deriva de mi convencimiento de que nuestras prácticas jurídicas, el conjunto de prácticas argumentativas o interpretativas que de hecho aceptamos en relación con la justificación jurídica final de decisiones, hacen del recurso a los principios o razones subyacentes a las prescripciones expresas un factor fundamental para la identificación de lo que con carácter final o concluyente cabe considerar como contenido del Derecho. A quien sostenga que eso no es así, que nuestras prácticas, por el contrario, conciben más bien el Derecho como lo que SCHAUER llamaría un «modelo de reglas radicalmente atrincherado» (en el que las formulaciones normativas se tratan siempre como opacas respecto a sus razones subyacentes) ${ }^{4}$, lo único que sabría —y seguramente podría - responderle es que la realidad desmiente su afirmación.

Pero BuLYGiN ${ }^{5}$ sostiene en su crítica que la distinción entre estos dos niveles es irrelevante para la discusión, porque, para decirlo sintéticamente, el modelo de Normative Systems sería neutral entre distintas concepciones acerca de cómo se identifica el Derecho, dado que se refiere en todo caso a sistemas de normas (que habrán sido identificadas a resultas de haber interpretado del modo que sea las formulaciones normativas emitidas por el legislador) y por tanto siempre a calificaciones normativas finales o concluyentes.

Ahora bien, que el modelo de Normative Systems sea o no completamente neutral entre distintas concepciones acerca de cómo se identifica el Derecho es una cosa, y que el propio BULYGIN tenga o no una concepción determinada al respecto (y que sea o no coincidente con la que a mí me parece acertada), otra bien distinta. Por cierto, creo que la concepción de BULYGIN acerca del modo en que se identifica el Derecho registró en algún momento cambios significativos ${ }^{6}$, pero eso aquí no interesa demasiado. Interesa más, me parece, constatar que al día de hoy nuestras concepciones sobre la identificación del Derecho siguen sin coincidir del todo. Creo que ello resulta patente cuando, en su crítica, BULYGIN afirma que de la consideración de los principios o razones subyacentes no puede resultar en ningún caso — en contra de lo que yo sostuve - una regulación determinada de casos no contemplados expresamente por las prescripciones emitidas por el legislador, porque ello supondría «ya no una mera explicitación, sino la creación de nuevas normas». Esta última afirmación me parece una petición de principio: sólo se puede mantener si se parte precisamente de dar por supuesto que no se identifica verdaderamente derecho preexistente cuando se derivan calificaciones normativas de la consideración de las razones subyacentes y de las rela-

4 Vid. F. SCHAUER, Las reglas en juego. Un examen filosófico de la toma de decisiones basada en reglas en el Derecho y en la vida cotidiana, trad. cast. de C. Orunesu y J. L. Rodríguez, Madrid-Barcelona, Marcial Pons, 2004, 110-112.

5 Y con él P. NAVARRO, op. cit. (en nota 1), 26-29.

6 Traté de documentarlo en J. C. BAYÓN, «Sobre el principio de prohibición y las condiciones de verdad de las proposiciones normativas», cit. (en nota 2), 62. 
ciones de prioridad entre las mismas para clases de casos, pero eso es precisamente lo que estamos discutiendo.

En cualquier caso, lo que aquí más importa es que, a mi modo de ver, su afirmación decidida de que la distinción entre los dos niveles aludidos sería irrelevante para la discusión vendría a desmentirla el propio BuLYGiN con uno de los argumentos de los que se sirve en su crítica: porque mi respuesta al mismo es que el argumento fracasa, entre otras cosas, precisamente por no tomar en cuenta adecuadamente la distinción entre calificaciones normativas prima facie y calificaciones normativas finales o concluyentes. El argumento en cuestión ${ }^{7}$ es el que viene a decir que, como ocurrió en cierto caso parece ser que relativamente célebre en Argentina, «[c]on bastante frecuencia los jueces civiles prohíben conductas no prohibidas por el Derecho y también ordenan realizar acciones que no son obligatorias», lo que mostraría que cabe acusarme «de ignorar cómo los jueces resuelven tales casos». El argumento merece dos tipos de comentarios. El primero, que yo no dije nada en absoluto acerca de lo que los jueces hacen, sino que sostuve cierta tesis acerca de lo que deben hacer. La tesis según la cual en ausencia de regulación el juez debe desestimar la demanda puede ser correcta o no, pero si no lo es no será ciertamente porque en un caso o en una cierta cantidad de ellos tengamos noticia de jueces que hicieron lo contrario. Y el segundo comentario es que la tesis en cuestión se refiere en todo caso, recuérdese, a calificaciones normativas finales o concluyentes. Es posible entonces que los jueces concluyan con frecuencia que conductas no prohibidas prima facie están a pesar de todo finalmente prohibidas (o que conductas no obligatorias prima facie sean sin embargo finalmente obligatorias), con lo cual, aun en ausencia de regulación explícita o prima facie, acaben condenando al demandado y haciéndolo realmente con arreglo a Derecho (al Derecho final o concluyente). Nada de esto desmiente, por sí solo, la idea de que en ausencia de regulación final o concluyente el juez debe desestimar la demanda. Y que BulYGIN haya podido sugerir lo contrario vendría a mostrarnos que, después de todo, insistir en la importancia de la distinción entre los dos niveles aludidos no era tan irrelevante para la discusión.

\section{3.}

En mi trabajo de 2009 afirmé que si cabía decir respecto de la conducta que el Derecho no regula que su realización era permisible —en el sentido específico de que el juez tendría el deber de desestimar cualquier demanda que pretendiese que la conducta en cuestión era obligatoria o estaba prohibida-, ello era tanto como decir que después de todo había al menos un sentido en el que el principio de prohibición («lo no prohibido está permitido») expresaba «una verdad no contingente y no trivial». Admito sin ambages que fue un error escribir eso, pero me parece que no fue exactamente la clase de error que no muy caritativamente me imputa BuLYGIN.

Fue un error porque, como ya he adelantado y trataré de explicar con detalle enseguida, comprendo ahora que no es posible mantener sin más que aquella afirmación sea «una verdad no contingente». Pero creo que no un error de la magnitud del que se

7 Que, sirviéndose además del mismo ejemplo, utiliza también P. NAVARRO, op. cit. (en nota 1), 23-24; y al que, no siendo en modo alguno novedoso, ya traté de dar respuesta en J. C. BAYÓN, «Sobre el principio de prohibición y las condiciones de verdad de las proposiciones normativas», cit. (en nota 2), 65-66. 
me atribuye, porque, para llegar a pensar que al hablar de «verdad no contingente y no trivial» quedaba atrapado en un dilema del que no podría salir a menos que estuviese pretendiendo nada menos que reivindicar la idea kantiana de juicios sintéticos a priori - $\mathrm{y}$ «a diferencia de KANT», remacha BULYGIN con ironía, sin decir «nada para justificarlos»-, es BULYGIN el que tiene que dar un paso que se me antoja demasiado rápido y que tampoco está precisamente exento de problemas.

En efecto, a su modo de ver, una verdad «no contingente y no trivial» tendría que ser por fuerza una verdad «necesaria pero no analítica»: y no habría tal cosa, salvo que uno sea tan osado como para tener en mente, sin ser precisamente KANT, juicios sintéticos a priori. Pero, naturalmente, el paso que da BulYGIN sólo se puede dar si se asume que un enunciado no trivial tiene que ser un enunciado no analítico, porque se asume a su vez que todas las verdades analíticas serían triviales. Y ocurre, como es bien sabido, que dar por sentado tal cosa nos lleva de cabeza a ese viejo y espinoso problema rastreable ya en el Menón platónico y al que, desde la crítica de LANGFORD a MOORE ${ }^{8}$, solemos referirnos hoy como «paradoja del análisis»: aclarar cómo un análisis conceptual puede ser a la vez correcto y verdaderamente informativo o esclarecedor, esto es, no trivial ${ }^{9}$. Ciertamente no es éste el momento ni el lugar para revisar las distintas vías propuestas para sortear la paradoja del análisis (ni menos aún, claro está, para internarse en las complejidades de la propia distinción analítico-sintético o para, a partir de ahí, discutir a la manera de QuiNE la noción misma de análisis conceptual), pero parece que las más prometedoras pasan precisamente por debilitar la férrea equiparación entre lo analítico y lo trivial (en el sentido de radicalmente no informativo) ${ }^{10}$. Y si «no trivial» no tiene por qué significar «no analítico» (en contra de lo que BuLYGIN está presuponiendo), haber calificado algo como «verdad no contingente y no trivial» pudo ser un error - $\mathrm{y}$ repito que no me duelen prendas en admitir que lo fue, en el sentido de que no era acertado calificarla sin más como «no contingente»—, pero no creo que me arroje inexorablemente por el despeñadero del desatino teórico al que BULYGIN piensa que me vi abocado.

\section{4.}

Pero en cualquier caso lo que importa aquí no es eso. Volviendo entonces al hilo central de la discusión, creo que la clave para desenredar todo este problema de la

8 Vid. C. H. LANGFORD, «The Notion of Analysis in Moore's Philosophy», en P. A. Schilpp (ed.), The Philosophy of G. E. Moore, Evanston-Chicago, Northwestern University Press, 1942, 321-342, así como la respuesta de G. E. MOORE, ibid., 660-667. También el comentario pionero de M. BLACK a la discusión entre LANGFord y MOORE: M. Black, «The Paradox of Analysis», Mind, núm. 53, 1944, $263-267$.

9 Simplificadamente, la paradoja reside en que dado un análisis del tipo «A es $B »$, donde $A$ es el analysandum y $B$ el analysans, o bien «A»y $« B »$ tienen el mismo significado, en cuyo caso parece que el análisis nos presentaría una identidad trivial, o bien no lo tienen, en cuyo caso el análisis sería incorrecto; y, en consecuencia, no habría análisis conceptual a la vez correcto y verdaderamente informativo o no trivial.

${ }^{10}$ Lo que requeriría descomponer de algún modo la idea de que el analysandum y el analysans «significan lo mismo». Haciendo un uso más o menos libre de la distinción de FREGE, un análisis sería entonces correcto si «A»

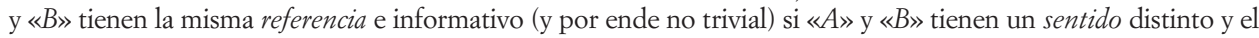
de «B» puede considerarse de alguna manera «más o mejor articulado». De ese modo, por ejemplo, «un triángulo isósceles es un triángulo isósceles» $\mathrm{y}$ «un triángulo isósceles es un polígono con tres lados, dos de los cuales tienen la misma longitud, y tres ángulos, dos de los cuáles son iguales» son ambos enunciados analíticos; pero el primero es claramente no informativo y trivial de un modo que no parece sensato predicar por igual del segundo. 
«asimetría» y la «equivalencia pragmática» se encuentra en el cap. VIII de Normative Systems y radica en la distinción que allí se presentaba entre «sistema primario» o «del ciudadano» ${ }^{11} \mathrm{y}$ «sistema secundario» o «del juez». A condición, eso sí, de que se entienda adecuadamente la forma precisa en que se articula la relación entre uno y otro. Me parece que ni en mi trabajo de 2009 ni en la posición mantenida invariablemente por BuLYGin desde Normative Systems se alcanza a hacerlo de manera plenamente satisfactoria. Los dos necesitamos corregir algo, aunque naturalmente la corrección requerida es distinta en cada caso. Y si cada uno de nosotros introdujese la corrección pertinente, a mi modo de ver nuestras posturas acerca de este punto se acabarían aproximando hasta hacerse prácticamente indistinguibles.

ALCHOURRÓN y BULYGIN llaman sistema primario o del ciudadano al «sistema de normas que regula la conducta de los sujetos del Derecho» y sistema secundario o del juez al «sistema de normas que regula la conducta de los jueces y demás órganos jurisdiccionales» $(I M C J S, 205)^{12}$, precisando además que las normas del sistema del juez son de dos tipos: «las que establecen en qué condiciones los jueces pueden juzgar y qué cuestiones pueden resolver (normas de competencia)» y «las que establecen obligaciones y prohibiciones a los jueces» (IMCJS, 208). Y mantienen que el sistema del ciudadano y el sistema del juez «están relacionados entre sí a través de la fundamentación de la sentencia» (IMCJS, 202), siendo en efecto la obligación de los jueces de fundar sus decisiones en Derecho la que «constituye el puente entre los dos sistemas» (IMCJS, 211).

Conviene entonces examinar con cuidado cómo entienden ALCHOURRÓn y BuLYGIN ese «puente». La respuesta — que vale la pena retener, porque es aquí donde está el núcleo del problema- es que para ellos el juez juzga conforme a Derecho si y sólo si funda sus decisiones en lo prescrito por el sistema del ciudadano:

«La obligación de fundar en Derecho una sentencia normativa es la exigencia de usar - para la fundamentación de ella— el sistema del [ciudadano] o sistema primario» (IMCJS, 213).

Está claro que, si se acepta esta idea básica, de ella se siguen de manera incuestionable tres consecuencias. La primera, que cuando el sistema del ciudadano califica como obligatoria para el demandado la conducta que el demandante le reclama, «el juez tiene obligación de condenar al demandado». La segunda, que cuando el sistema del ciudadano establece que al demandado le está permitido abstenerse de hacer lo que el demandante pretende que haga, «el juez tiene la obligación de rechazar la demanda». Y la tercera — y crucial para lo que aquí interesa-, que si del sistema del ciudadano «no se infiere que el demandado tenga la obligación de realizar el acto en cuestión, pero tampoco se infiere que le está permitido abstenerse de realizarlo», esto es, si el sistema del ciudadano no dice nada acerca de la conducta del demandado, entonces «el juez no tiene ninguna obligación específica, ni la de condenar ni la de rechazar la demanda» (IMCJS, 215).

11 ALCHOURRÓN y BULYGIN hablaban allí de «sistema primario» o «del súbdito» [cfr. Introducción a la metodología de las ciencias jurídicas y sociales, cit. (en nota 1), 205; en la versión original en inglés se empleaba la expresión «subject system»: cfr. Normative Systems, Wien-New York, Springer Verlag, 1971, 148]. Pero me parece preferible hablar de sistema «del ciudadano» y me consta que BULYGIN concuerda conmigo en esto.

${ }_{12}$ Desde este momento las referencias a la versión castellana de Normative Systems -Introducción a la metodología de las ciencias jurídicas y sociales, cit. (en nota 1) - aparecen entre paréntesis en el texto con la abreviatura IMCJS seguida del correspondiente número de página. 
Obsérvese que todo esto —y señaladamente lo último— no son sino implicaciones indiscutibles del postulado del que parten ALCHOURRÓN y BULYGIN: a saber, que el juez juzga conforme a Derecho si y sólo si funda sus decisiones en lo prescrito por el sistema del ciudadano. Si esto se acepta, me parece que efectivamente no habría modo de negar que cuando el sistema del ciudadano no prescriba nada acerca de la conducta del demandado, ninguna decisión que el juez dicte — tanto si es la de acoger la demanda como la de rechazarla- podría considerarse «conforme a Derecho» o «fundada en Derecho». Y claro está, decir que ninguna decisión de las posibles podría considerarse fundada en Derecho es tanto como decir que el Derecho deja al juez en una posición de discrecionalidad a la hora de resolver: que, por supuesto, es justamente lo que de manera constante ha venido manteniendo BULYGIN desde Normative Systems hasta el artículo que se incluye en este volumen de Doxa.

Pero lo que ocurre, en mi opinión, es que lo discutible es precisamente aquel postulado del que parte. Pensar — como piensan AlChOURRÓN y BULYGIN— que el juez juzga conforme a Derecho si y sólo si funda sus decisiones en lo prescrito por el sistema del ciudadano es tanto como decir que el ordenamiento sólo puede imponer al juez un deber de decidir en un sentido determinado si el sistema del ciudadano prescribe algo acerca de la conducta del demandado (ya sea que está obligado a realizarlo, ya que le está permitido abstenerse de realizarlo). Y no creo que esto sea cierto. Por supuesto, ALCHOURRÓN y BULYGIN tienen razón cuando afirman que «[e]s evidente que si el sistema primario nada dice acerca del status deóntico de la conducta del demandado, el juez no puede cumplir con la obligación de fundar su decisión [cualquiera que sea] en ese sistema» (IMCJS, 217; la cursiva es mía). Pero lo que no parecen advertir - y sin embargo resulta aquí decisivo- es que el hecho de que no puedan fundarla en ese sistema, en el sistema primario, no supone necesariamente que no puedan fundarla en Derecho ${ }^{13}$ : porque, sencillamente, cabe que puedan fundarla en una norma del sistema secundario o del juez. Recuérdese que el sistema del juez consta de normas de competencia y de normas que «establecen obligaciones y prohibiciones a los jueces». Y si resultase que forma parte del sistema secundario o del juez una norma que le obliga a desestimar toda demanda en la que la pretensión de la parte actora sea que el demandado realice una acción acerca de cuyo status deóntico nada dice — no meramente prima facie, sino concluyentemente- el sistema del ciudadano (y que, por consiguiente, con arreglo a dicho sistema primario el demandado no tiene la obligación de realizar), entonces sería indiscutible que el Derecho no dejaría en tal caso al juez en una posición de discrecionalidad, sino que, por el contrario, le estaría imponiendo el deber de fallar en un sentido perfectamente determinado: el de rechazar la demanda. Y en ese supuesto su decisión de desestimar la pretensión del actor estaría indubitadamente fundada en Derecho, a pesar, nótese bien, de que por hipótesis el sistema del ciudadano no diría nada acerca de la conducta del demandado.

Realmente no acierto a ver de qué modo podría ponerse en tela de juicio esta conclusión. Pero lo que ahora me interesa resaltar es que ni fue exactamente esto lo que sostuve en mi trabajo de 2009, ni tampoco es exactamente lo que desde Normative Systems hasta la actualidad ha venido sosteniendo expresamente BULYGIN. Por eso he ido

${ }^{13}$ Una posibilidad, repito, que parece que ALCHOURRÓN y BULYGIN no contemplan: insisten de hecho en que si la decisión del juez «no está fundada en el sistema primario», entonces «viola el deber de juzgar conforme al Derecho» (IMCJS, 218). 
anticipando que a mi juicio cada uno de nosotros tenía que introducir alguna corrección en su posición de partida y que ello, además, las haría converger de manera significativa. Empezaré subrayando de qué modo lo que se acaba de decir corrige lo que sostuve en el trabajo que BULYGIN critica. Por supuesto, es contingente que exista o no una norma en el sistema del juez que le obligue a rechazar la demanda cuando el sistema del ciudadano no diga nada acerca del status deóntico de la conducta del demandado. Como yo mismo apuntaba — si bien es cierto que hablando de otra cosa: de la diferencia entre permiso protegido y permiso no protegido-, si existe una obligación ha de ser porque existe una norma que la impone ${ }^{14}$ : y esto vale tanto para las obligaciones que puedan tener los ciudadanos como para las que puedan tener los jueces. De lo que se sigue, es cierto, que si no existiese en el Derecho una norma que obligase a los jueces a desestimar toda demanda en la que se pretenda que el demandado haga algo que según el sistema primario no tiene la obligación de hacer (y es incuestionable que podría no existir), entonces no sería correcto afirmar — como, sin las debidas precisiones y matizaciones yo afirmabaque cuando el Derecho no establece nada respecto al caso el juez tiene la obligación de fallar en el sentido, perfectamente determinado, de rechazar la demanda.

En suma, en sentido estricto ALCHOURRÓN y BULYGIN tenían razón cuando calificaban como errónea la tesis según la cual «la mera afirmación de que el demandado no tiene la obligación que el actor le atribuye es un fundamento suficiente para la sentencia denegatoria» (IMCJS, 220; la cursiva es mía). Tenían razón porque lo que fundamentaría de manera suficiente la sentencia desestimatoria sería la ausencia de la obligación del demandado junto con la obligación del juez, cuando una norma del sistema secundario la establezca y sólo si la establece, de desestimar en tal caso la demanda. Ahora bien, lo que ocurre es que una norma semejante, por más que como toda norma sea sin duda contingente, existe de hecho en todos nuestros sistemas jurídicos ${ }^{15}$. Ésta es, no cabe duda, una pura cuestión empírica: pero no tengo noticia de un solo sistema jurídico real en el que el juez no tenga el deber de desestimar una demanda con la que el actor pretenda que se obligue al demandado a hacer algo que según el sistema primario no tiene el deber (concluyente) de realizar. La insistencia en que las cosas podrían ser de otro modo es, desde el punto de vista teórico, impecable. Pero un rasgo contingente puede ser sin embargo importante a la hora de caracterizar los sistemas jurídicos reales. Y no sé si un tipo de teoría del Derecho pronta a desdeñar lo que es verdadero en relación con los sistemas jurídicos reales porque no lo es necesariamente en relación con todos los sistemas jurídicos posibles ${ }^{16}$ es realmente el más interesante.

14 Vid. J. C. BAYÓN, «Sobre el principio de prohibición y las condiciones de verdad de las proposiciones normativas», cit. (en nota 2), 67.

15 P. NAVARRO —op. cit. (en nota 1), 25-26- ha sostenido que «es dudoso» que realmente sea así y que, de todos modos, lo único que se habría mostrado «en el mejor de los casos» es que «en algunos sistemas [la cursiva es suya]» el juez debe rechazar la demanda si el demandante no tiene derecho a que el demandado haga lo que el actor pretende. Sus dudas respecto a la existencia en nuestros sistemas de una norma que impone ese deber al juez derivan, como ya apunté, de un argumento que no distingue adecuadamente entre calificaciones normativas prima facie y calificaciones normativas concluyentes. En cuanto a su apreciación de que como mucho ésa será la situación «en algunos sistemas», si fuese acaso la aserción positiva de que se da sólo en unos pocos de los sistemas jurídicos reales, y no meramente una forma de repetir que no tiene por qué darse en todo sistema jurídico concebible, me parece que sencillamente no se correspondería con la realidad.

$16 \mathrm{Y}$ tampoco hay que ser naîf en relación con este punto: asoma aquí el problema teórico, cualquier cosa menos sencillo, de determinar qué rasgos «necesarios»o «definitorios» habría de tener algo para contar como «un sistema jurídico» posible. 
Pero, aun con tales reservas, cabría preguntarse si admitiendo lo que aquí he admitido no he acabado, lisa y llanamente, dando por buena sin más la posición que siempre ha sostenido BULYGIN. Creo que no. Y explicar por qué nos lleva finalmente a la cuestión de qué es lo que entiendo que, por su parte, habría de conceder BULYGIN. Si mi error fue sugerir que basta con que el sistema del ciudadano no establezca nada acerca de la conducta del demandado para que el juez deba rechazar la demanda, el error de BULYGIN radica en sostener que basta con que el sistema del ciudadano no establezca nada acerca de la conducta del demandado para que el juez no tenga ningún deber determinado ${ }^{17}$. Y ninguna de las dos cosas es cierta. No lo es la primera, porque la ausencia de regulación en el sistema primario no es suficiente para que el juez tenga el deber específico de desestimar (hará falta, además, una norma del sistema secundario que en dicho supuesto le imponga ese deber). Ni tampoco es cierta la segunda, porque de la ausencia de regulación en el sistema primario no se sigue necesariamente que no tenga ningún deber específico (en concreto, no se seguirá si, como sucede de hecho en nuestros sistemas jurídicos, existe en el sistema del juez una norma que le impone en tal caso la obligación de desestimar) ${ }^{18}$.

Una vez aceptado por mi parte que la ausencia de regulación en el sistema primario no es fundamento suficiente del deber del juez de desestimar, ¿no acabaría disolviéndose nuestro desacuerdo respecto de esta cuestión específica si, por su parte, aceptara BULYGIN que la regulación en el sistema primario no es necesaria para que el juez pueda tener dicho deber? A mí me parece que sí.

17 Y no creo que pueda discutirse que eso es exactamente lo que sostiene BULYGIN. Se sostenía ya en Normative Systems, donde se decía que «si el sistema del [ciudadano] nada dice acerca de la conducta del demandado, el juez no tiene ninguna obligación específica» (IMCJS, 215; la cursiva es del original) y, de modo aún más claro y terminante, que «la solución de un caso individual sólo está justificada si se halla fundada en el sistema primario, es decir, si es la misma solución que ese sistema correlaciona con el caso genérico correspondiente» (IMCJS, 220-221; la cursiva es mía). Y BuLYGIN mantiene esa posición en el trabajo incluido en este volumen, donde reitera que «en ausencia de toda norma referida a la conducta del demandado [...] el juez no tiene ninguna obligación específica» (la cursiva es mía).

${ }^{18}$ Creo que concebir del modo descrito la relación entre sistema primario o del ciudadano y sistema secundario o del juez sirve también para disolver las paradojas a las que BULYGIN me enfrenta. En su opinión, mi punto de vista me aboca a dos conclusiones absurdas: «que todo caso que por hipótesis no está regulado (mera no prohibición) está regulado» y que «todo caso para el cual por hipótesis no hay consecuencias normativas en el sistema (caso no prohibido), en realidad tiene consecuencias normativas en el sistema». Pero creo que las paradojas se disipan si, introduciendo aquí la diferencia esencial entre sistema primario y sistema secundario, se dice que un caso puede no estar regulado (mera no prohibición) en el sistema primario estando en cambio regulado en el sistema secundario qué es lo que el juez debe fallar al respecto, de manera que aun no habiendo «consecuencias normativas en el sistema» (del ciudadano), hay en realidad «consecuencias normativas en el sistema» (del juez). 